\title{
Reconceptualizing family caregivers as part of the health care team
}

\author{
Amber L. Stephenson ${ }^{1}$, Minakshi Raj ${ }^{2}$, Samuel C. Thomas ${ }^{3,4}$, Erin E. Sullivan ${ }^{5}$, Matthew J. DePuccio ${ }^{6}$, \\ Bram Fleuren $^{7}$, Ann Scheck McAlearney ${ }^{8}$ \\ ${ }^{1}$ David D. Reh School of Business, Clarkson University, Schenectady, NY, USA; ${ }^{2}$ Department of Kinesiology and Community Health, College of Applied \\ Health Sciences, University of Illinois at Urbana-Champaign, Champaign, IL, USA; ${ }^{3}$ Stanford School of Medicine, Stanford, CA, USA; ${ }^{4}$ Intermountain \\ Healthcare, Salt Lake City, UT, USA; ${ }^{5}$ Department of Healthcare Administration, Sawyer Business School, Suffolk University, Boston, MA, USA; \\ ${ }^{6}$ Department of Health Systems Management, College of Health Sciences Rush University, Chicago, IL, USA; ${ }^{7}$ Psychology and Neuroscience, Maastricht \\ University, Maastricht, The Netherlands; ${ }^{8}$ Department of Family and Community Medicine and Executive Director, Center for the Advancement of Team \\ Science, Analytics, and Systems Thinking (CATALYST), College of Medicine, The Ohio State University, Columbus, OH, USA \\ Correspondence to: Associate Professor Amber L. Stephenson, PhD, MPH. David D. Reh School of Business, Clarkson University, 80 Nott Terrace, \\ Schenectady, NY 12308, USA. Email: astephen@clarkson.edu.
}

Received: 25 July 2021; Accepted: 08 October 2021; Published: 25 June 2022.

doi: $10.21037 /$ jhmhp-21-56

View this article at: https://dx.doi.org/10.21037/jhmhp-21-56

\section{Introduction}

Family and friends who serve as caregivers are becoming increasingly important in supporting adults to complete various tasks such as transportation, shopping, and health care responsibilities like medication management (1). It is estimated that the number of adults older than 65 in the United States will nearly double in the next four decades (2), and over $80 \%$ of family caregivers of older adults are responsible for coordinating care between and among providers (3). However, the inclusion of these caregivers in the health care delivery process lacks recognition, coordination and standardization (4). Despite efforts to include caregivers (e.g., through informal or formal proxy access to their care recipient's patient portal), policies and procedures around caregiver inclusion are complex and inconsistently implemented (5).

One policy, the Caregiver Advise, Record, Enable (CARE) Act, was developed by AARP, then introduced to state legislatures, and is intended to provide designated caregivers with discharge instructions and guidance. The CARE Act, now signed into law by 40 states, aims to provide health care providers with practices that integrate caregivers into the process of care delivery, but has failed to be broadly implemented within health care organizations (6). A national survey of health care executives, clinical leaders, and clinicians about caring for caregivers found that $79 \%$ of respondents are either not very familiar or not at all familiar with the CARE Act (6). Medicaid waivers are intended to provide caregivers with training and, in some cases, compensation; yet these efforts are uncoordinated across the U.S. (5). Tools have also been developed to offer caregivers shared access to electronic health records. Yet a significant issue remains: how are caregivers ultimately included in the team itself?

Understanding caregiver inclusion in healthcare teams is essential to maximize the benefits they have to offer for improving patient outcomes. Most centrally, team-based patient care can be understood as an information sharing/ distribution of expertise problem, in which the optimal care solution might depend on important information that is not shared among members of the care team (7). For instance, a patient may receive information about wound care from their doctor during a visit, but the caregiver responsible for overseeing the wound care may not directly receive those instructions from the provider. This type of communication gap may then result in negative patient outcomes. More dramatically, health care teams failing to adequately include the caregiver's unique perspective may make suboptimal treatment decisions.

In this commentary, we discuss considerations surrounding caregiver inclusion in health care teams and outline the implications of caregiver engagement for 
policy and practice. Questions we aim to address include: what are barriers to caregiver engagement in care teams? What are important implications of caregiver inclusion on team dynamics? How can status and identity issues be handled when including caregivers in care teams? And, to what extent should the caregiver's role in a care team be formalized? We finalize by synthesizing answers to these questions into policy implications that may facilitate more effective inclusion of caregivers in care teams.

\section{Considering the caregiver}

There is an opportunity to reimagine the structure of health care teams to include caregivers and improve delivery of and oversight of optimal patient care. To do so, there are several influential factors that should be considered such as levels of engagement, the nature of teamwork itself, the roles of professional identity and hierarchy in healthcare, and the boundaries between formal and informal work.

\section{Caregiver engagement}

The factors and conditions affecting caregiver engagement with health care teams are varied. To begin, the Department of Health and Human Services acknowledges patient and caregiver engagement as an important strategy for improving patient safety (8). Although caregivers can offer unique perspectives about the health and safety of patients (9), caregivers may not always have the opportunities or platforms to voice their concerns or engage in an ongoing dialogue with care team members (10). Deliberations between caregivers and formal care team members may also be shortened due to physician time constraints and payment models that incentivize volume over value (11). Consequently, conversations to develop care plans that involve both patients and caregivers may be challenging to effectively implement.

Other factors such as caregivers having insufficient time and training to engage with care team members (12) may also preclude their engagement with the care team. For example, without clear guidance or direction, the caregiver may perceive the care they provide to their patient as separate and distinct from the care provided by other clinicians or formal health care team members. With this cognitive separation between informal and formal care, the needs and preferences of family caregivers may not be addressed-potentially making these caregivers feel isolated from the patient-provider decision-making process. In an effort to close the distance between formal and informal care, and to integrate the caregiver into the health care team, health organizations should strive to make it easier for caregivers to adopt and use telehealth tools (e.g., patient portals) to ask questions, seek information, and monitor patients during care transitions between health care settings (13).

\section{Team dynamics}

Considering the caregiver as part of the health care team has strong implications for understanding team dynamics in care delivery. In a recent study, health care executives, clinical leaders, and clinicians indicated that unpaid caregivers should be viewed as members of the care team, though they tend to get far less support and recognition than deserved (6). Traditionally, health care teams are interdisciplinary, with varied roles and responsibilities allocated based on professional background and training (14). The degree to which team membership is stable depends on the discipline or setting in which the team operates; more agile teams are able to adjust their membership based on patient needs (15). Also, as discussed in the next section, physicians are typically viewed as at the top of a rigid hierarchy (16) when it comes to patient care. While these team characteristics may be historically normative, they create barriers to involvement of, and collaboration with, caregivers. As a result, caregivers may be reluctant to speak up to ask questions, provide pertinent information, or advocate for their patient's preferences.

In order to effectively integrate caregivers, multidisciplinary health care teams must clearly define the team, including team members, roles, and responsibilities (17). Furthermore, the team needs to have a shared view or philosophy about caregiving, the role of caregivers on the team, and the value of including caregivers as team members (17). To achieve this integration, health care teams should adopt a shared commitment to patient and family-centered care and promote a culture of learning and inclusivity that maximizes the competencies of the caregiver and demonstrates willingness to welcome new knowledge that the caregiver brings to the team.

\section{Role of professional identity and status}

Conceptualizations of professional identity and a strict hierarchy may threaten caregiver engagement and could have implications for patient health outcomes. The 
professional identity of health care team members consists of the attitudes, values, knowledge, beliefs and skills shared with members within a professional group (18). These various elements of professional identity are powerful drivers of health professionals' behavior, particularly if they identify strongly and the professional identity is salient in formal caregiver-professional interactions (19). For example, traditional beliefs regarding the position of a health care professional in society as 'superior', 'expert' or 'savior' $(20,21)$, may spur salient status differences that could prevent caregivers from feeling empowered to speak up. It is well-known that professional identity as it is perceived by both the professional and the caregiver includes a sense of expertise and corresponding expert power (22). Therefore, in an effort to better include the caregiver into the care team, it is paramount that health professionals are aware of their power position and use it to welcome caregivers to voice perspectives and concerns (23). This will require positive attitudes towards caregivers, valuing their perspective, and having the competence to communicate these attitudes and values effectively. It also requires identifying the expertise of the caregiver as a key informant complementing the professional skills of the clinical team. Given the importance of medical training in professional identity construction, the more prominent role of caregivers in society should be paid attention to in teaching current and future professionals the appropriate attitudes, values, knowledge, beliefs and skills to foster positive exchange (24). Moreover, as hierarchies in medicine are reinforced by payment models, policies should consider compensation to caregivers for their active role in supporting their patient in the home. As an example, the state of Illinois compensates family caregivers through Medicaid for their efforts in caregiving responsibilities (25).

\section{Boundaries between formal and informal work}

Identifying the various roles of caregivers within the health care team can provide a theoretical basis for future investigation into boundaries between informal and formal work, as well as into teams and teamwork in contexts where strict boundaries are observed. A care team that views caregivers as external to, or outside of, the care team can build trusting, collaborative, supportive relationships with caregivers once agreement is reached that all are collectively working in the patient's best interest (26). In this circumstance, the work of a caregiver is considered informal but still supports the common interests of the patient and their team. As informal work, however, this work is not necessarily built into the expectations of the overall care process, and the care team remains in charge of the care of that patient. While this gives caregivers flexibility in their involvement and reduces the risk of liability, it also means that there is power asymmetry in the extent to which caregivers are invited and/or accepted.

In contrast, when the work of a caregiver is formally defined, care team members may rely on that caregiver to perform certain tasks and regularly interact with the team itself. The implications of this classification are substantial, and if a caregiver does not understand their formal roleas previously noted, gaps in both communication and care can result. With an expectation that the caregiver's work is formal, additional challenges may arise given that the caregiver is not a regular member of the care team, and thus may not trust nor have rapport with existing team members. Furthermore, as that caregiver is only concerned about a single patient, perceptions about conflicting priorities of the other team members who are caring for multiple patients may be problematic. Establishing clear expectations and boundaries becomes especially important when defining and formalizing caregiver work to manage both relationships among team members and caregivers to support highquality patient care. These points illustrate the importance of clearly defining the caregiver role in the provision of care for each individual patient.

\section{Implications for policy and practice}

Reconceiving the role of the caregiver as an active member of the health care team has substantial implications for policy and practice. For instance, studies report greater satisfaction among older patients when they are accompanied by a family caregiver, and high levels of engagement in communication between physicians and patients when caregivers are present (27). This suggests that the successful utilization of family caregivers in the process of care delivery has the potential to influence patient outcomes as well as clinician practices. Older adults and caregivers themselves express a desire for being better integrated in the health care team so that they can more effectively coordinate care and carry out their day-to-day responsibilities (28). Consequently, there is a heightened focus on creating policy to support the anticipated increased need for in-home and community-based care to serve the aging demographic (2).

Preparing caregivers to be active participants in the 
care recipient's health care team will likely require that health systems recognize both caregivers' strengths and limitations as they relate to their abilities to follow care team recommendations, communicate proactively with clinicians, and mobilize support to address the needs of care recipients. For instance, health systems and care teams may consider adapting existing care referral criteria to account for both care recipient and caregiver needs and preferences to promote safer and more effective transitions between health care settings. System-level interventions that facilitate inclusion may ultimately encourage health care teams to engage in perspective-taking that further promotes caregiver involvement and patient-centered care. Furthermore, interventions that target caregivers with low health literacy may also help improve care recipient engagement in self-management behaviors and potentially reduce barriers to navigating and arranging for health and support services. Thus, education programs and interventions to improve caregiver health literacy may positively impact the health outcomes of patients who frequently interact with the health care system.

To date, health policy involving caregivers has been unable to achieve substantial impact in the U.S. Greater efforts are needed to increase awareness about existing caregiver policies and enact new caregiver policies that enable caregivers to be active members of the care team. As suggested, integrating caregivers requires policies that acknowledge the full scope and nature of family caregiving and recognize the value that family caregivers bring to the health care team (5). These policies could manifest in changes to national laws and policies, such as compensation to caregivers for their efforts outside health care, for instance, by expanding Medicaid waivers that provide reimbursement for these types of supports. Not only are caregivers often placed under significant financial burden due to their roles as caregivers, but the economic value of the unpaid care and support provided by caregivers is estimated at $\$ 470$ billion annually in the U.S. (3). Policies directed towards compensating caregivers, while offered in some states through Medicaid waivers, have yet to be adopted nationwide; however these policies have been implemented in other countries in the form of financial support such as paid work leave and tax benefits, as well as through non-financial support like training, education, and respite care $(29,30)$. These policy decisions reflect the heterogeneity in cultural and societal recognition of the tremendous work of caregivers and its value. Financial incentives through reimbursement of clinician time have also yet to materialize, although the shift of the U.S. healthcare industry from fee-for-service reimbursement systems to value-based care may prompt health systems and providers to enact their own policies around integrating caregivers into the care team in an effort to improve the value of the care provided to patients. For example, organizational policies could introduce incentives for clinicians to better integrate caregivers such as by evaluating process measures around documentation of family caregivers in the health record.

\section{Conclusions}

With an aging population and greater care needs, the role of the caregiver will only continue to become more prominent in health care. Determining feasible approaches to include caregivers in the health care delivery process could facilitate improvements in clinical practice and can be translated into actionable guidance for health care organizations, providers, and caregivers as well.

\section{Acknowledgments}

Funding: None.

\section{Footnote}

Provenance and Peer Review: This article was commissioned by the Guest Editors (Stephen J. O'Connor, Nancy Borkowski and Katherine A. Meese) for the series "Shaping Tomorrow's Healthcare Systems: Key Stakeholders' Expectations and Experiences" published in Fournal of Hospital Management and Health Policy. The article has undergone external peer review.

Peer Review File: Available at https://jhmhp.amegroups.com/ article/view/10.21037/jhmhp-21-56/prf

Conflicts of Interest: All authors have completed the ICMJE uniform disclosure form (available at https://jhmhp. amegroups.com/article/view/10.21037/jhmhp-21-56/coif). The series "Shaping Tomorrow's Healthcare Systems: Key Stakeholders' Expectations and Experiences" was commissioned by the editorial office without any funding or sponsorship. The authors have no other conflicts of interest to declare.

Ethical Statement: The authors are accountable for all 
aspects of the work in ensuring that questions related to the accuracy or integrity of any part of the work are appropriately investigated and resolved.

Open Access Statement: This is an Open Access article distributed in accordance with the Creative Commons Attribution-NonCommercial-NoDerivs 4.0 International License (CC BY-NC-ND 4.0), which permits the noncommercial replication and distribution of the article with the strict proviso that no changes or edits are made and the original work is properly cited (including links to both the formal publication through the relevant DOI and the license). See: https://creativecommons.org/licenses/by-nc-nd/4.0/.

\section{References}

1. AARP and National Alliance for Caregiving. Caregiving in the United States 2020. AARP 2020. Available online: https://www.aarp.org/ppi/info-2020/caregiving-in-theunited-states.html

2. Available online: https://khn.org/news/article/caringfor-an-aging-nation/?utm_medium=email\&utm_ source=rasa_io \&PostID $=31128149 \&$ MessageRunDetail $\mathrm{ID}=5381526004$

3. Reinhard SC, Feinberg LF, Choula R, et al. Valuing the invaluable: 2015 update. Insight on the Issues 2015;104:89-98. Available online: https://www.aarp.org/ content/dam/aarp/ppi/2015/valuing-the-invaluable2015-update-new.pdf

4. Wolff JL, Freedman VA, Mulcahy JF, et al. Family Caregivers' Experiences With Health Care Workers in the Care of Older Adults With Activity Limitations. JAMA Netw Open 2020;3:e1919866.

5. Raj M, Singer PM. Redefining Caregiving as an Imperative for Supporting Caregivers: Challenges and Opportunities. J Gen Intern Med 2021. [Epub ahead of print]. doi: 10.1007/s11606-021-06932-0.

6. Gondi S, Berchuck SI, Brown RT, et al. A Community Partnership to House and Care for Complex Patients with Unstable Housing. NEJM Catal Innov Care Deliv 2021. [Epub ahead of print]. doi: 10.1056/cat.21.0158.

7. Mitchell PH, Wynia MK, Golden RL, et al. Core principles \& values of effective team-based health care. National Academy of Medicine 2012. doi: 10.31478/201210c.

8. U.S. Department of Health and Human Services, Office of Disease Prevention and Health Promotion. National Action Plan for Adverse Drug Event Prevention 2014.
9. Sharma AE, Rivadeneira NA, Barr-Walker J, et al. Patient Engagement In Health Care Safety: An Overview Of Mixed-Quality Evidence. Health Aff (Millwood) 2018;37:1813-20.

10. Garvelink MM, Ngangue PA, Adekpedjou R, et al. A Synthesis Of Knowledge About Caregiver Decision Making Finds Gaps In Support For Those Who Care For Aging Loved Ones. Health Aff (Millwood) 2016;35:619-26.

11. Scholl I, Kobrin S, Elwyn G. "All about the money?" A qualitative interview study examining organizational- and system-level characteristics that promote or hinder shared decision-making in cancer care in the United States. Implement Sci 2020;15:81.

12. Fields B, Rodakowski J, Leighton C, et al. Including and Training Family Caregivers of Older Adults in Hospital Care: Facilitators and Barriers. J Nurs Care Qual 2020;35:88-94.

13. Bennett WL, Pitts S, Aboumatar H, et al. Strategies for Patient, Family, and Caregiver Engagement. Rockville, MD, USA: Agency for Healthcare Research and Quality, 2020.

14. Andreatta PB. A typology for health care teams. Health Care Manage Rev 2010;35:345-54.

15. Doherty RB, Crowley RA; Health and Public Policy Committee of the American College of Physicians. Principles supporting dynamic clinical care teams: an American College of Physicians position paper. Ann Intern Med 2013;159:620-6.

16. Nembhard IM, Edmondson AC. Making it safe: The effects of leader inclusiveness and professional status on psychological safety and improvement efforts in health care teams. J Organ Behav 2006;27:941-66.

17. Doekhie KD, Buljac-Samardzic M, Strating MMH, et al. Who is on the primary care team? Professionals' perceptions of the conceptualization of teams and the underlying factors: a mixed-methods study. BMC Fam Pract 2017;18:111.

18. Adams K, Hean S, Sturgis P, et al. Investigating the factors influencing professional identity of first-year health and social care students. Learning in Health and Social Care 2006;5:55-68.

19. Mitchell R, Boyle B. Professional diversity, identity salience and team innovation: The moderating role of openmindedness norms. J Organ Behav 2015;36:873-94.

20. Dowd M. Decoding the God complex. New York Times 2011.

21. Lupton D. Doctors on the medical profession. Social Health \& Illn 1997;19:480-97.

22. French JR, Raven B, Cartwright D. The bases of social 
power. In: Shafritz JM, Ott S, Jang YS. editors. Classics of Organization Theory. Belmont, CA, USA: Thomson Wadsworth, 2005.

23. Kuluski K, Kokorelias KM, Peckham A, et al. Twelve principles to support caregiver engagement in health care systems and health research. Patient Exp J 2019;6:141-8.

24. Goldie J. The formation of professional identity in medical students: considerations for educators. Med Teach 2012;34:e641-8.

25. Illinois Compiled Statutes: Family Caregiver Act Springfield, Illinois: Legislative General Assembly of Illinois. Available online: https://www.ilga.gov/legislation/ ilcs/ilcs3 .asp?ActID=2610\& ChapterID $=31$

26. Haverhals LM, Manheim C, Gilman C, et al. Dedicated to the Mission: Strategies US Department of Veterans Affairs Home-Based Primary Care Teams Apply to Keep Veterans

doi: $10.21037 /$ /hmhp-21-56

Cite this article as: Stephenson AL, Raj M, Thomas SC, Sullivan EE, DePuccio MJ, Fleuren B, McAlearney AS. Reconceptualizing family caregivers as part of the health care team. J Hosp Manag Health Policy 2022;6:20. at Home. J Am Geriatr Soc 2019;67:2511-8.

27. Fortinsky RH. Family Caregiver Assessment in Primary Care: How to Strengthen the HealthCare Triad? J Am Geriatr Soc 2021;69:286-8.

28. Raj M, Platt JE, Anthony D, et al. What Does "PatientCentered" Mean? Qualitative Perspectives from Older Adults and Family Caregivers. Gerontol Geriatr Med 2021;7:23337214211017608.

29. Courtin E, Jemiai N, Mossialos E. Mapping support policies for informal carers across the European Union. Health Policy 2014;118:84-94.

30. Calvó-Perxas L, Vilalta-Franch J, Litwin H, et al. What seems to matter in public policy and the health of informal caregivers? A cross-sectional study in 12 European countries. PLoS One 2018;13:e0194232. 